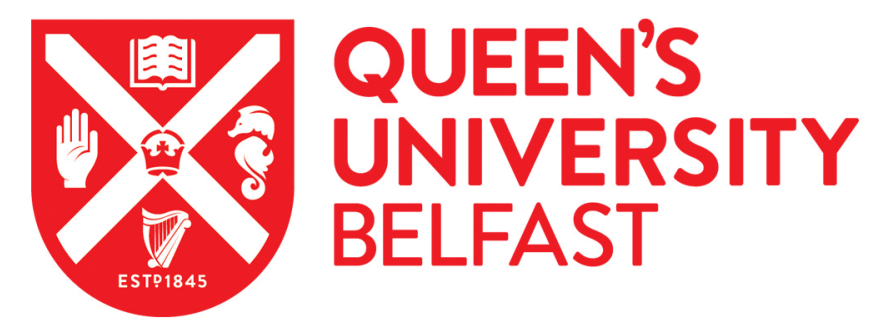

\title{
Diet quality is more strongly related to food skills rather than cooking skills confidence: Results from a national cross-sectional survey
}

Lavelle, F., Bucher, T., Dean, M., Brown, H. M., Rollo, M., \& Collins, C. E. (2019). Diet quality is more strongly related to food skills rather than cooking skills confidence: Results from a national cross-sectional survey. Nutrition \& Dietetics Journal. https://doi.org/10.1111/1747-0080.12583

Published in:

Nutrition \& Dietetics Journal

Document Version:

Peer reviewed version

Queen's University Belfast - Research Portal:

Link to publication record in Queen's University Belfast Research Portal

Publisher rights

(C) 2019 Dietitians Association of Australia. This work is made available online in accordance with the publisher's policies. Please refer to any applicable terms of use of the publisher.

\section{General rights}

Copyright for the publications made accessible via the Queen's University Belfast Research Portal is retained by the author(s) and / or other copyright owners and it is a condition of accessing these publications that users recognise and abide by the legal requirements associated with these rights.

Take down policy

The Research Portal is Queen's institutional repository that provides access to Queen's research output. Every effort has been made to ensure that content in the Research Portal does not infringe any person's rights, or applicable UK laws. If you discover content in the Research Portal that you believe breaches copyright or violates any law, please contact openaccess@qub.ac.uk. 


\section{Abstract:}

2 Aim: While diet quality has declined globally, the promotion of cooking skills as a potential target to

3

4 counter the decline has been proposed.. The aim of the current study was to investigate the relationship between food and cooking skills and diet quality in Australian adults.

Methods: A sample of 910 Australian adults completed an online cross-sectional survey to evaluate their level of cooking and food skills confidence, food related psychological variables, diet quality using the Australian Recommended Food Score (ARFS) and sociodemographic characteristics.

Analysis of variance with posthoc analysis, Pearson's correlations and hierarchical multiple regressions were conducted using IBM SPSS V25, with statistical significance set at $p<0.05$.

Results: Older respondents and females reported higher levels of both cooking and food skills confidence compared younger and male participants, all $\mathrm{p}<0.001$. Cooking and food skills confidence scores were highly correlated( $\mathrm{r}=.70, \mathrm{p}<0.001)$, but weakly correlated with ARFS $(\mathrm{r}=.22, \mathrm{p}<0.001 ; \mathrm{r}$ $=.31, \mathrm{p}<0.001$, respectively). Participants with higher diet quality scores had greater cooking and food skills confidence and they consumed less takeaway food ( $<<0.001$ and $p=.006$, respectively). Sixteen percent of the variance in ARFS was accounted for, with age, sex, food creativity and food skills confidence significant contributing the most variability.

Conclusions: Strategies to improve food skills confidence could potentially enhance diet quality and variety to a greater degree than focusing on cooking skills alone. However, development of both skills sets should be encouraged within education programs and targeted to differing aspects of diet quality. Tailoring interventions to specific population groups with low confidence in their skills, including younger adults and males, may facilitate individuals in making healthy food choices.

Keywords: Australian Recommended Food Score, Cooking, Diet Quality, Food skills, Survey 


\section{Introduction:}

42 The global decline in diet quality ${ }^{1}$ has reignited interest in home cooking and the ways in which

43 people prepare food to be eaten at home, as a potential strategy to reverse this decrease. ${ }^{2}$ Research to

44 date has focused on the consumption of food where the preparation has been completely removed

45 from the consumer, such as take away foods, meals eaten in restaurants and ready-made meals or pre-

46 packaged foods requiring no preparation and their impact on diet quality and dietary intake. ${ }^{2-4}$ More

47 recently, research has concentrated on investigating home meal preparation and a reported transition

48 from 'cooking from scratch' to the use of convenience products in home food preparation..$^{5-8}$ Research 
from the US shows that from the 1960's to the 2000's, there was a significant decrease in time spent in home meal preparation (equating to 35-36 minutes/day) and in percentage of daily energy consumed from home food sources..$^{9}$ Poti, Barry and Popkin et al., ${ }^{10}$ showed similar patterns emerging for children in the US, with the percentage of daily energy eaten away from home increasing from $23.4 \%$ to $33.9 \%$ from the 1970 's to the 2000 's. Furthermore, food prepared away from home contained more calories per eating occasion and this type of food was higher in saturated fat and total fat on a per-calorie basis. ${ }^{11}$ This domestic culinary transformation has been attributed to a reduction in overall diet quality internationally., ${ }^{32}$ This implied link warrants further investigation.

Underpinning a change in home cooking frequency and approaches, has been a reported reduction in the level of cooking skills and frequency of their use. ${ }^{7,8,13}$ This reduction has been attributed to lack of time, changes in traditional family roles with greater participation of women in the workforce, and greater availability and affordability of convenience foods and food products. ${ }^{4,7,14-17}$ For optimal nutrient intakes, it is recommended that a varied and balanced diet be consumed. ${ }^{18} \mathrm{~A}$ greater level of cooking skills has been shown to be associated with a higher diet quality and linked to specific components of the diet. ${ }^{19-21}$ However, the role that cooking and food skills play in achieving varied and healthful dietary patterns has not been well studied. Although some research suggests that diet quality in Australia may have improved, ${ }^{22}$ research has shown that both diet quality and variety within nutrient-rich core foods are not optimal in Australia ${ }^{23}$ and that improvements are warranted in order to lower diet-related health risks. The importance of evaluating both cooking and food skills confidence to meaningfully influence diet quality through comprehensive and targeted interventions has been previously emphasised. ${ }^{5}$ For this study, cooking and food skills have been defined in line with McGowan et al. ${ }^{5}$, in that cooking skills are considered a set of physical or mechanical skills used in food preparation such as mixing and chopping. Whereas, food skills include the wider components of home meal preparation such as meal planning, food shopping and budgeting. Thus, the current study's objectives were to investigate the relationship between cooking and food skills and overall diet quality in a diverse sample of Australian adults through a cross-sectional survey.

\section{Design and Sampling}


Australian adults were recruited to complete a cross-sectional online survey from August 2016-

August 2017 to ensure seasonal variability in cooking was addressed. Survey inclusion criteria were aged greater than 18 years and residing in Australia. The target sample size was 1000 participants, in line with a recent survey undertaken on the island of Ireland (IOI) (Northern Ireland and Republic of Ireland) with a final sample of 1049 adults. ${ }^{20,24}$ Participant recruitment strategies included sharing a survey link via websites and social media, traditional flyers in the [removed for blind peer review] and surrounding areas, convenience sampling with previously established research connections, media releases and a news story for [removed for blind peer review]. Furthermore, a panel that previously completed the 'Healthy Eating Quiz' were contacted. ${ }^{23}$ Participants volunteered to complete the survey and were incentivised on completion by being entered into a prize draw for one of five AUD $\$ 100$ department store gift vouchers. This study aligned with guidelines set down in the Declaration of Helsinki and ethical approval was obtained from by the [removed for blind peer review].

This research is reported in line with Strengthening the Reporting of Observational studies in Epidemiology (STROBE) Statement. ${ }^{25}$ The survey was administered online using programme Qualtrics (Qualtrics, Provo, UT). Potential participants were able to access the survey using the link on the advertisements. The information statement regarding the research appeared before the survey. Those who chose to participate were instructed to click 'next' to continue on to the survey and were informed that this would be considered as their informed consent to partake in the study. The next screen visible to the participants was used to confirm eligibility, with those eligible then able to progress on to complete the survey. Socio-demographic information such as age, sex, education level and socioeconomic status (SES) classified using Socio-Economic Indexes for Areas (SEIFA) percentiles ${ }^{26}$, was obtained. Below is a description of the measures included in this study. 
The survey was modelled on the one described in McGowan et al., ${ }^{20}$ which assessed the influence of sociodemographic, knowledge- and psychological-related variables alongside perceived cooking and food skills on diet quality.

\section{Cooking and Food Skills}

The development and validation of the cooking skills confidence and food skills confidence measures have been described in detail elsewhere. ${ }^{27}$ These measures were included in the current survey with minor amendments to wording to make them applicable to the Australian context. Participants rated on a seven point Likert scale how good they felt they were in performing $(1=$ very poor, $7=$ very good) 14 cooking skills and 19 food skills. The individual ratings were summed to create an overall cooking skills confidence score and a food skills confidence score.

\section{Psychological and other Food Related variables}

Cooking identity, food creativity, food neophilia, and take away consumption were all measured using the same methods found in the IOI survey. ${ }^{20,24}$ Briefly, cooking identity, meaning how much the participant viewed themselves as a cook, was measured using seven items, where participants indicated on a five point Likert scale ( $1=$ strongly agree, $5=$ strongly disagree) how much they agreed or disagreed with each of the seven items. These items were summed to create a cooking identity score. Food creativity followed the same format as the cooking identity scale, although there were only six items in the scale. Again, food neophilia was calculated in a similar manner as the other two scales, but with three items in the scale. Practical nutrition knowledge was measured with the brief PKB-7 scale. ${ }^{28}$

\section{Health Related Variables}

Health consciousness was measured using questions derived from The Health and Taste Attitude Scales (HTAS) developed by Roininen et al., ${ }^{29}$. BMI was calculated using participant self-reported height and weight.

\section{Diet Quality Assessment}


Diet quality was measured using the Australian Recommended Food Score (ARFS), a short foodbased validated diet quality index developed to measure alignment of usual dietary patterns with the Australian Dietary Guidelines. ${ }^{30}$ It focuses on variety in intake within the nutrient-rich, core food groups in the Australian Guide to Healthy Eating. The ARFS has eight-subscales with 20 questions related to vegetables, 12 for fruit, 12 for breads and cereals, 10 for dairy foods, 7 for meat/flesh foods, 6 for non-meat/flesh protein foods, 2 for spreads/sauces and 1 for water. In relation to scoring, most foods are awarded one point for a consumption frequency of $\geq$ once per week, which varies based on the item and food group. ${ }^{30}$ The total ARFS score is calculated by summing the points for each item and total scores range from zero to 73 . For those indicating they were vegetarian, zero points were awarded for the meat sub-scale. A vegetarian sub-scale was created with the same maximum points where each vegetarian alternative item selected was scored double points, with a bonus point awarded when both the soybeans and lentils questions were selected. ${ }^{23}$ For some analyses participants were divided into quartiles based on the ARFS scores; Q1 representing lowest diet quality, Q2 consisting of low to medium diet quality scores, Q3 consisting of medium to higher diet quality and Q4 representing high diet quality. The quartile cut off points were derived from the norms of the population data from 92,000 participants in a study by Williams and colleagues. ${ }^{23}$

\section{Data Analysis}

All data were analysed using IBM SPSS statistics version 25. Descriptive statistics (Means (M), standard deviations (SD), etc.) were used to explore the data according to diet quality. ANOVAs with Scheffe posthoc analysis ${ }^{31}$ (to account for unequal group sizes) were conducted to assess any significant differences between the different levels of diet scores, as well as for examining the differences in cooking and food skills across sociodemographic variables. Normality and homogeneity of variance was assessed, using Levene's test. Where homogeneity of variance did not meet the assumptions of homogeneity of variance, Welch's ANOVA was used. Pearson's correlations were used to assess relationships between cooking skills and food skills confidence and ARFS scores, nutrition knowledge and BMI. Finally, hierarchical multiple regressions were conducted to assess predictor variables for ARFS scores. All analysis was considered significant at a level of 0.05 . 
Results

154 A total of 920 participants completed the survey. Ten responses were removed during the data

155 cleaning process; four for a duration less than $50 \%$ of the median time taken to complete the survey,

156 four duplicates based on IP address and contact information, two were aged $<18$ years. The final

157 sample included 910 participants, predominantly female (80.2\%), with a mean BMI which classified

158 them as overweight $\left(\mathrm{M}=25.41 \mathrm{~kg} / \mathrm{m}^{2}, \mathrm{SD}=5.60 \mathrm{~kg} / \mathrm{m}^{2}\right)$ and a mean age of 45.2 years $(\mathrm{SD}=16.08$

159 years). The majority had an undergraduate degree (35.2\%), reported a higher socioeconomic

background (57.3\%) and were married (48.4\%). A complete overview Table of sociodemographic

characteristics of the sample can be found in the supplementary material (S1). Table 1 summarises

differences in cooking and food skill confidence by sociodemographic variables. There was a

significant difference in cooking and food skills confidence based on age and sex, with those who

were older having both higher cooking and food skills confidence compared to younger adults. In

addition, females had higher cooking and food skills confidence compared to males.

Table 1: Differences in cooking skills (CS) confidence and food skills (FS) confidence by sociodemographic subgroups $(\mathrm{n}=910)$

\begin{tabular}{|c|c|c|c|c|c|c|c|}
\hline Characteristic & & $\begin{array}{l}\text { CS } \\
\text { confidence }\end{array}$ & $F(d f)$ & $\begin{array}{l}\text { p- } \\
\text { value }\end{array}$ & $\begin{array}{l}\text { FS } \\
\text { confidence }\end{array}$ & F (df) & $\begin{array}{l}p- \\
\text { value }\end{array}$ \\
\hline & & M (SD) & & & M (SD) & & \\
\hline \multirow[t]{4}{*}{ Age } & $\begin{array}{l}18-29 \\
\text { years } \\
(\mathrm{N}=206)\end{array}$ & $\begin{array}{l}76.70 \\
(12.11)^{\mathrm{a}}\end{array}$ & & & $\begin{array}{l}106.02 \\
(15.40)^{\mathrm{a}}\end{array}$ & & \\
\hline & $\begin{array}{l}30-45 \\
(\mathrm{~N}=261)\end{array}$ & $\begin{array}{l}78.07 \\
(12.75)^{\mathrm{ac}}\end{array}$ & & & $\begin{array}{l}105.50 \\
(16.26)^{\mathrm{a}}\end{array}$ & & \\
\hline & $\begin{array}{l}46-60 \\
(N=254)\end{array}$ & $\begin{array}{l}81.46 \\
(13.15)^{b c}\end{array}$ & & & $\begin{array}{l}110.36 \\
(16.91)^{b}\end{array}$ & & \\
\hline & $\begin{array}{l}61+ \\
(\mathrm{N}=189)\end{array}$ & $\begin{array}{l}81.09 \\
(14.23)^{\mathrm{c}}\end{array}$ & $\begin{array}{l}7.02 \\
(3,906)\end{array}$ & $<0.001$ & $\begin{array}{l}111.29 \\
(15.83)^{b}\end{array}$ & $\begin{array}{l}7.49 \\
(3,906)\end{array}$ & $<0.001$ \\
\hline \multirow[t]{2}{*}{ Sex } & $\begin{array}{l}\text { Male } \\
(\mathrm{N}=176)\end{array}$ & $\begin{array}{l}75.43 \\
(14.92)^{\mathrm{a}}\end{array}$ & & & $\begin{array}{l}103.35 \\
(17.01)^{\mathrm{a}}\end{array}$ & & \\
\hline & $\begin{array}{l}\text { Female } \\
(\mathrm{N}=734)\end{array}$ & $\begin{array}{l}80.27 \\
(12.55)^{b}\end{array}$ & $\begin{array}{l}19.50 \\
(1,908)\end{array}$ & $<0.001$ & $\begin{array}{l}109.34 \\
(15.97)^{b}\end{array}$ & $\begin{array}{l}19.42 \\
(1,908)\end{array}$ & $<0.001$ \\
\hline \multirow[t]{2}{*}{ Education } & $\begin{array}{l}\text { Postgrad } \\
(\mathrm{N}=291)\end{array}$ & $\begin{array}{l}79.33 \\
(14.17)\end{array}$ & & & $\begin{array}{l}109.32 \\
(16.37)\end{array}$ & & \\
\hline & $\begin{array}{l}\text { Undergrad } \\
(\mathrm{N}=320)\end{array}$ & $\begin{array}{l}80.15 \\
(12.18)\end{array}$ & & & $\begin{array}{l}108.88 \\
(15.93)\end{array}$ & & \\
\hline
\end{tabular}




\begin{tabular}{|l|l|l|l|l|l|l|l|}
\hline & $\begin{array}{l}\text { Lower } \\
\text { than Uni } \\
(\mathrm{N}=299)\end{array}$ & $\begin{array}{l}78.45 \\
(13.18)\end{array}$ & $\begin{array}{l}1.30 \\
(2,907)\end{array}$ & NS & $\begin{array}{l}106.32 \\
(16.63)\end{array}$ & $\begin{array}{l}2.95 \\
(2,907)\end{array}$ & 0.053 \\
\hline SES $^{(a)}$ & Low & $\begin{array}{l}77.89 \\
(15.01)\end{array}$ & & & $\begin{array}{l}109.61 \\
(17.38)\end{array}$ & & \\
\hline & Medium & $\begin{array}{l}80.43 \\
(12.38)\end{array}$ & & & 107.98 & & \\
& High & $\begin{array}{l}79.31 \\
(13.00)\end{array}$ & $\begin{array}{l}1.50 \\
(2,886)\end{array}$ & NS & $\begin{array}{l}108.40 \\
(15.99)\end{array}$ & .358 & NS \\
\hline
\end{tabular}

CS; Cooking skills, FS; Food skills, SES; Socioeconomic status

(df; degrees of freedom, F; F-statistic, M; Mean, SD; Standard deviation

Superscript letters depict where significant differences $(\mathrm{p}<0.05)$ fall between the groups, statistical tests conducted include independent t-tests and ANOVAs

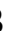

The differences in cooking and diet quality indicators across quartiles of ARFS are reported in Table

2. Those with the higher ARFS scores (quartiles 3 and 4) had significantly greater cooking skills confidence compared to those with lower ARFS scores (quartile 1 and 2). For food skills confidence, those in the highest quartiles (Q3 and Q4) had greater food skills confidence than those in quartile 1, with quartile 4 having greater food skills confidence scores than all other quartiles. For food creativity and cooking identity, those in quartile 3 were more creative and saw themselves as being a cook more than those in quartile 1. Participants from quartile 4 were the most creative and saw themselves as a cook more than any other quartile. Participants in quartile 3 and 4 were more open to trying new foods than quartile 1 , with those in quartile 3 being the most open to trying new foods. Additionally, those in quartiles 3 and 4 consumed less take away than those in quartiles 1 and 2 . Furthermore, quartiles 3 and 4 had a greater nutrition knowledge scores than those in quartile 1. 
Table 2: Differences between diet quality using the Australian Recommended Food Score quartiles on cooking and health related variables (Q1;

lowest scores; Q4; highest)

\begin{tabular}{|c|c|c|c|c|c|c|c|c|}
\hline & $\begin{array}{l}\text { Range } \\
\text { in } \\
\text { sample }\end{array}$ & $\begin{array}{l}\text { Overall } \\
\text { sample }\end{array}$ & $\mathbf{F}(\mathbf{d f})$ & $\begin{array}{l}\text { Q1 (N=165) } \\
{[<33]}\end{array}$ & $\begin{array}{l}\text { Q2 (N=204) } \\
{[33-38]}\end{array}$ & $\begin{array}{l}\text { Q3 (N=347) } \\
{[39-46]}\end{array}$ & $\begin{array}{l}\text { Q4 (N=192) } \\
{[47+]}\end{array}$ & Significance \\
\hline & & $\mathrm{M}(\mathrm{SD})$ & & $\mathrm{M}(\mathrm{SD})$ & $\mathrm{M}(\mathrm{SD})$ & $\mathrm{M}(\mathrm{SD})$ & $\mathrm{M}(\mathrm{SD})$ & $p$-value \\
\hline \multicolumn{9}{|l|}{ Cooking + food skills } \\
\hline Cooking skills confidence & $21-98$ & $79.33(13.19)$ & $13.74(3,904)$ & $\begin{array}{l}74.76 \\
(15.78)^{\mathrm{a}}\end{array}$ & $\begin{array}{l}77.53 \\
(13.94)^{\mathrm{a}}\end{array}$ & $80.75(11.39)^{b}$ & $82.62(11.58)^{b}$ & $<.001$ \\
\hline Food skills confidence & $55-133$ & $\begin{array}{l}108.22 \\
(16.31)\end{array}$ & $28.77(3,904)$ & $\begin{array}{l}100.07 \\
(18.37)^{\mathrm{a}}\end{array}$ & $\begin{array}{l}106.37 \\
(16.27)^{\mathrm{b}}\end{array}$ & $\begin{array}{l}109.44 \\
(14.97)^{\mathrm{b}}\end{array}$ & $\begin{array}{l}115.01 \\
(13.25)^{\mathrm{c}}\end{array}$ & $<.001$ \\
\hline \multicolumn{9}{|l|}{\begin{tabular}{|l|} 
Cooking attitudes \\
\end{tabular}} \\
\hline Food creativity & $6-30$ & $19.65(4.81)$ & $14.57(3,904)$ & $18.12(5.20)^{\mathrm{a}}$ & $\begin{array}{l}19.00 \\
(4.68)^{\mathrm{ab}}\end{array}$ & $19.88(4.75)^{\mathrm{b}}$ & $21.22(4.17)^{\mathrm{c}}$ & $<.001$ \\
\hline Cooking identity & $7-35$ & $27.69(5.41)$ & $16.68(3,904)$ & $25.77(6.13)^{\mathrm{a}}$ & $\begin{array}{l}26.91 \\
(5.60)^{\mathrm{ab}}\end{array}$ & $28.07(5.13)^{\mathrm{b}}$ & $29.47(4.32)^{\mathrm{c}}$ & $<.001$ \\
\hline Food neophilia & $3-15$ & $12.32(2.84)$ & $10.19(3,904)$ & $11.38(3.24)^{\mathrm{a}}$ & $\begin{array}{l}12.07 \\
(2.76)^{\mathrm{ab}}\end{array}$ & $12.75(2.61)^{\mathrm{c}}$ & $12.62(2.76)^{\mathrm{bc}}$ & $<.001$ \\
\hline \multicolumn{9}{|l|}{ Diet quality } \\
\hline Consumption of takeaway & $1-6$ & $2.12(0.87)$ & $13.75(3,904)$ & $2.36(1.00)^{\mathrm{a}}$ & $2.29(0.87)^{\mathrm{a}}$ & $2.03(0.77)^{\mathrm{b}}$ & $1.88(0.81)^{\mathrm{b}}$ & .006 \\
\hline \multicolumn{9}{|l|}{$\begin{array}{l}\text { Health + wellbeing } \\
\text { indicators }\end{array}$} \\
\hline BMI & $\begin{array}{l}15.24- \\
59.03 \\
\end{array}$ & 25.41 & $2.46(3,880)$ & $26.19(6.22)$ & $25.71(5.75)$ & $24.83(4.81)$ & $25.48(6.14)$ & .054 \\
\hline Nutrition knowledge & $1-7$ & $4.71(1.28)$ & $6.00(3,892)$ & $4.36(1.34)^{\mathrm{a}}$ & $4.67(1.30)^{\mathrm{ab}}$ & $4.80(1.23)^{\mathrm{b}}$ & $4.89(1.24)^{\mathrm{b}}$ & $<.001$ \\
\hline
\end{tabular}
variable - Cooking skills confidence ${ }^{26}: 0-98$, Food skills confidence ${ }^{26}: 0$ - 133, Food creativity ${ }^{20,24}: 6$ - 30, Cooking identity ${ }^{20,24}: 7$ - 35, Food neophilia ${ }^{20,24}: 3-15$,

Consumption of Takeaway ${ }^{20,24}: 1-6$, Nutrition Knowledge ${ }^{27}: 1-7$. Superscript letters depict where significant differences $(p<0.05)$ fall between the groups 
190 An overview of the unadjusted correlations between cooking and food skills confidence, ARFS

191 scores, BMI and nutrition knowledge are reported in Table S2, Supporting Information. As expected, 192 cooking skills and food skills confidence were highly correlated $(r=.70, p<0.001)$. Cooking and food 193 skills confidence were also weakly correlated with ARFS total scores $(r=.22, p<0.001 ; r=.31$, $194 \mathrm{p}<0.001$, respectively).

195 Table 3 summarises the results of a hierarchical multiple regression analysis predicting the relationship between sociodemographic, knowledge and psychological and meal preparation variables and total ARFS scores. The baseline model included sociodemographic factors, which accounted for $6 \%$ of the variance in ARFS scores, with a significant independent contribution ( $p<0.001)$. The addition of knowledge and psychological food related variables to the model, explained a further $7 \%$ to the variance $(\mathrm{p}<0.001)$. In the final model additional variables related to meal preparation were added and this accounted for $16 \%(\mathrm{p}<0.001)$ of the variance in ARFS score. The variables contributing most significantly to explain the variance in the final model included age, sex, food creativity and food skills confidence (Table 3). 
Table 3: Hierarchical multiple regression predicting Total ARFS scores

\begin{tabular}{|c|c|c|c|c|c|c|}
\hline \multirow{2}{*}{$\begin{array}{l}\text { ARFS Total }(\mathrm{N}=686)^{(a)} \\
\text { Variables }\end{array}$} & \multicolumn{2}{|l|}{ Model 1} & \multicolumn{2}{|l|}{ Model 2} & \multicolumn{2}{|l|}{ Model 3} \\
\hline & B (SE) ${ }^{(\mathbf{b})}$ & $\boldsymbol{\beta}^{(\mathbf{b})}$ & B (SE) ${ }^{(\mathbf{b})}$ & $\boldsymbol{\beta}^{(\mathbf{b})}$ & B (SE) ${ }^{(b)}$ & $\boldsymbol{\beta}^{(\mathbf{b})}$ \\
\hline \multicolumn{7}{|l|}{ Sociodemographic } \\
\hline Age & $.094(.020)$ & $.177 * * *$ & $.118(.020)$ & $.223 * * *$ & $.084(.022)$ & $.159 * * *$ \\
\hline Sex & $3.238(.741)$ & $.162 * * *$ & $2.818(.738)$ & $.141 * * *$ & $2.373(.745)$ & $.119 * *$ \\
\hline Education & $-.193(.405)$ & -.018 & $.116(.392)$ & .011 & $.148(.388)$ & .014 \\
\hline Income & $.639(.264)$ & $.093^{*}$ & $.530(.256)$ & $.077 *$ & $.552(.256)$ & $.080 *$ \\
\hline SES $^{\text {(a) }}$ & $-.013(.013)$ & -.036 & $-.012(.013)$ & -.035 & $-.012(.012)$ & -.035 \\
\hline BMI & $-.178(.059)$ & $-.118 * *$ & $-.161(.057)$ & $-.106^{* *}$ & $-.079(.060)$ & -.052 \\
\hline \multicolumn{7}{|l|}{$\begin{array}{l}\text { Knowledge \& Psychological } \\
\text { variables }\end{array}$} \\
\hline Nutrition knowledge & & & $.633(.251)$ & $.097 *$ & $.613(.248)$ & $.094 *$ \\
\hline Food neophilia & & & $.328(.122)$ & $.112 * *$ & $.266(.126)$ & $.091 *$ \\
\hline Food creativity & & & $.316(.071)$ & $.182 * * *$ & $.254(.074)$ & $.146^{* *}$ \\
\hline \multicolumn{7}{|l|}{ Meal preparation } \\
\hline Cooking skills confidence & & & & & $-.039(.034)$ & -.061 \\
\hline Food skills confidence & & & & & $.084(.027)$ & $.162 * *$ \\
\hline Consumption of takeaway & & & & & $-.907(.382)$ & $-.095 *$ \\
\hline $\mathbf{F}^{(\mathbf{b})}$ & \multicolumn{2}{|l|}{$8.384 * * *$} & \multicolumn{2}{|l|}{$12.797 * * *$} & \multicolumn{2}{|l|}{$11.560 * * *$} \\
\hline Adjusted R $\mathbf{R}^{2(b)}$ & \multicolumn{2}{|l|}{$.061 * * *$} & \multicolumn{2}{|l|}{$.134 * * *$} & \multicolumn{2}{|l|}{$.156 * * *$} \\
\hline
\end{tabular}

205 (a) ARFS; Australian Recommended Food Score, SES; Socioeconomic status

206 (b) B; Unstandardised beta-coefficient, $\beta$; Standardised beta-coefficient, F; F-statistic, R2; R-squared statistic; SE; Standard error

$207 * \mathrm{p}<0.05 ; * *=\mathrm{p}<0.01 ; * * *=\mathrm{p}<0.001$ 
208 Hierarchical multiple regression models in terms of variables predicting the individual ARFS sub-

209 scales were conducted, an overview of the model for each sub-scale can be found in the Table S3,

210 Supporting Information. The most variance significantly explained by the models was for the

211 prediction of the vegetable sub-scale, predicting $25 \%$ of the variance $(\mathrm{p}<0.001)$. The most significant

212 predictor variables for this model were age, sex, food creativity, consumption of take away, food

213 skills confidence, nutrition knowledge and food neophilia. The next two models found to explain a

214 greater amount of variance were those for the fruit and animal protein sub-scales (13\% and 12\%,

215 respectively). The most significant predictor variables for the ARFS fruit sub-scale were age, sex and

216 negatively with higher BMI being negative predictor. For the animal protein/meat sub-scale, which

217 excluded fish, the most significant predictors were income and BMI 
219

To the best of our knowledge this is the first large Australian study to investigate the relationship between cooking and food skills confidence and overall diet quality. The current study highlighted that food skills may be of greater importance than cooking skills in terms of the relationship with higher diet quality. In addition, food skills confidence was the greatest potentially modifiable predictor of diet quality as measures by ARFS scores, contributing significantly to the variance explained in the final model. Drilling down further, food creativity and food skills confidence were the greatest potentially modifiable variables predicting vegetable sub-scale scores.

Recent research has focused on the importance of cooking skills for improving diet quality. ${ }^{19}$ However, the current study suggests that food skills, the wider components in meal preparation such as planning, shopping and budgeting, may be of greater importance in terms of dietary variety and nutritional quality of the overall usual diet. Although the promotion of home meal preparation has had a resurgence in recent years, a majority of the focus is on the practical component of cooking skills. The current study highlights that food skills have potentially been a neglected aspect of home food preparation that could be harnessed to influence diet quality and variety. Food skills need to be emphasised more as essential skills within programs seeking to improve cooking skills as a strategy to improve diet-related health. That cooking skills are not the only important variable in terms of consuming a varied diet has been shown previously in an older population. ${ }^{32}$ This may be due to a range of factors including that food skills cover a wide variety of skills that relate to planning, budgeting, and resourcefulness which are all key to the ability to source and use a variety of ingredients and leftover foods.

As well as food skills, the other significant potentially modifiable predictor of vegetable variety was food creativity, imagination and creativity surrounding food and creating new meal ideas or adapting recipes. To date, there has been little research conducted on domestic food creativity, with previous research focusing on professional culinary innovation. ${ }^{33-35}$ Food creativity is likely to be an important element within future nutrition interventions in order to inspire achievement of a varied intake of healthy food by teaching food creativity. This could be achieved by supplying ingredients to the 
participants and they have to create a meal out of the ingredients, or by taking left over ingredients and creating a new meal, this could initially begin as examples from the instructors and a group brainstorming activity and then progress to individual decisions. The role of domestic food creativity is mirrored in the rise of TV cooking shows, YouTube channels, and social media posts and blogs dedicated to food. However, their focus is not health, but indulgence, or in the case of some social media influencers to rebel against nutrition science and to promote fad diets. ${ }^{36-39}$ This could potentially be a key medium to interact with in order to encourage creativity within healthy food recipes.

McGowan et al.,${ }^{20}$ demonstrated similar findings in relation to cooking and food skills in regard to sociodemographic characteristics. Older participants had greater cooking and food skills confidence than younger participants, with females having greater skills confidence than males. Older participants having greater confidence than younger participants may indicate that the reported culinary transition, or the transformation of home meal preparation to include more convenience processed foods and less skills ${ }^{5-7}$ is being seen in Australia. Although alternatively, this may suggest that confidence in cooking skills grows with age.

Both cooking skills and food skills confidence were correlated with diet quality as measured by ARFS, albeit weakly. Those who had higher ARFS scores had higher levels of cooking skills and food skills confidence, were more creative, identified themselves more as cooks, were more open to trying new foods and reported eating less takeaway than those with lower ARFS scores. For the ARFS subscales, the largest amount of variance was explained for the vegetable sub-scale. The most significant potentially modifiable predictors were food creativity, consuming less take away and food skills confidence. This research has reinforced the concept that cooking and food skills are related to a healthful diet. These skills are important in terms of enabling consumers to consume a healthy diet. The novel, brief validated ARFS measure has also been shown to correlate with nutrition knowledge, with a higher nutrition knowledge being correlated with a higher diet quality. 
271 While links between diet quality and cooking skills have been previously shown, ${ }^{20,40}$ the importance

272 of food skills as a separate factor associated with overall diet quality have not. The current research

273 specifically highlights that food-based education programs both within the educational system and conducted as part of outreach nutrition programmes need to include both cooking skills and food skills and not emphasise one component over the other. Each sets of skills separately influence components related to achieving a well-balanced healthy dietary intake..$^{20}$

277 Future research could apply the current findings in an experimental design, such as measuring the impact of a cooking and food skills education intervention on dietary intake and examine whether improving these skills improves diet quality, intake and variety. Additionally, those receiving formal Home Economics education, that incorporates both cooking and food skills, could be followed up in a prospective cohort to assess their diet quality and how this tracks over time, post-education, to determine whether this form of education has an enduring impact. Recent retrospective research has shown that those who had some form of Home Economics education had greater food knowledge than those who did not, which in turn may lead to more optimal food choices in an Australian cohort. ${ }^{13}$

Furthermore, the current study has reinforced the differences in cooking and food skills confidence between males and females ${ }^{20}$. With the rising increase in the proportion of males taking the role of the 'at home parent', and a greater number of men individually habiting, there is a need to more clearly understand this disparity in order to inform methods to address it. A detailed investigation into men's cooking, food and dietary behaviours and skills may be beneficial in terms of contributing to this under researched area.

\section{Strengths and Limitations}

There are a number of strengths in the current study, including the large sample size, the use of validated measures for cooking and food skills ${ }^{27}$ and diet quality, ${ }^{30}$ and the length of time for data collection to allow for seasonal variability. These strengths in the research design may help to enhance previous research to enable researchers to focus their interventions, such as including food skills, and to identify at risk groups. However, there are a number of limitations that need to be 
acknowledged when interpreting the results. While a varied sample was sought, the final sample were predominantly females, with a relatively high education and SES. However, the current results provide some insights into the current state of cooking and food skills and diet quality in Australian adults and is likely a best case scenario. It would be expected that those from lower socioeconomic status and lower education would have less cooking and food skills confidence in line with the IOI study ${ }^{20}$ and a study of Brisbane residents where participants with a lower education and lower household income were less confident in cooking vegetables ${ }^{41}$ Future studies should target those of lower SES and educational attainment and males by targeting recruitment to areas where there are large numbers, including workplaces and clubs, and using relevant incentives and strategies to generate a nationally representative sample to improve generalisability. As with all cross-sectional research, causality cannot be determined in this study and future intervention research could evaluate the impact on diet quality of interventions aimed at improving food and cooking skills.

Greater food skills confidence could potentially optimise diet quality and variety, to a greater extent than cooking skills confidence. This may be due to the wide range of skills captured within the food skills domain, including, budgeting, shopping and resourcefulness, which may help in including a wide variety of foods in the diet. Additionally, this study re-emphasised discrepancies in cooking and food skills confidence among different population groups with younger adults and males having lower skills. This supports the need for targeting interventions to specific groups in order to empower individuals in optimising their food choices and overall diet quality.

\section{Acknowledgements}

The authors thank the survey respondents.

\section{Supporting Information}

321 Table S1: Sociodemographic Characteristics of Australian Sample

Table S2: Correlations between cooking skills (CS) confidence and food skills (FS) confidence and the Australian Recommended Food Score (ARFS), Nutrition knowledge (NK) and Body Mass Index 
325 Table S3: Final model of multiple regressions predicting subscale scores of the Australian 326 Recommended Food Score (ARFS)

327

328

329 
1. Popkin BM. Global nutrition dynamics: the world is shifting rapidly toward a diet linked with noncommunicable diseases. Am J Clin Nutr. 2006;84(2):289-98.

3332 2. Wolfson JA, Bleich SN. Is cooking at home associated with better diet quality or weight-loss

3. Monteiro CA, Levy RB, Claro RM, de Castro IR, Cannon G. Increasing consumption of ultraprocessed foods and likely impact on human health: evidence from Brazil. Public Health Nutr. 2011;14(1):5-13.

4. Buckley M, Cowan C, McCarthy M. The convenience food market in Great Britain: convenience food lifestyle (CFL) segments. Appetite. 2007;49(3):600-17.

5. McGowan L, Caraher M, Raats M, Lavelle F, Hollywood L, McDowell D, et al. Domestic cooking and food skills: A review. Crit Rev Food Sci Nutr. 2017;57(11):2412-31.

6. Worsley T, Ismail S, Wang WC, Wijeratne P, Ridley S. Who cooks from scratch and how do they prepare food? Br Food J 2015;117(2):664-76.

7. Beck ME. Dinner preparation in the modern United States. Br Food J 2007;109(7):531-47.

8. Lang T, Caraher M. Is there a culinary skills transition? Data and debate from the UK about changes in cooking culture. Journal of the HEIA. 2001;8(2):2-14.

9. Smith LP, Ng SW, Popkin BM. Trends in US home food preparation and consumption: analysis of national nutrition surveys and time use studies from 1965-1966 to 2007-2008. Nutr J. 2013;12(1):45.

10. Poti JM, Popkin BM. Trends in energy intake among US children by eating location and food source, 1977-2006. J Am Diet Assoc. 2011;111(8):1156-64.

11. Guthrie JF, Lin BH, Frazao E. Role of food prepared away from home in the American diet, 1977-78 versus 1994-96: changes and consequences. J Nutr Educ Behav. 2002;34(3):140-50.

12. Monteiro CA, Moubarac JC, Cannon G, Ng SW, Popkin B. Ultra-processed products are becoming dominant in the global food system. Obes Rev. 2013;14 Suppl 2:21-8.

13. Worsley A, Wang WC, Yeatman H, Byrne S, Wijayaratne P. Does school health and home economics education influence adults' food knowledge? Health Promot Int. 2016;31(4):925-35.

14. Brunner TA, van der Horst K, Siegrist M. Convenience food products. Drivers for consumption. Appetite. 2010;55(3):498-506.

15. Scholderer J, Grunert KG. Consumers, food and convenience: The long way from resource constraints to actual consumption patterns. J Econ Psychol. 2005;26(1):105-28.

16. Caraher M, Lang T. Can't cook, won't cook: A review of cooking skills and their relevance to health promotion. Int J Health Promot Educ. 1999;37(3):89-100.

17. Gofton L. Dollar rich and time poor?: Some problems in interpreting changing food habits. $\mathrm{Br}$ Food J 1995;97(10):11-6.

18. National Health and Medical Research Council (NHMRC). Eat for Health: Australian Dietary Guidelines2013 Available from: https://www.eatforhealth.gov.au/sites/default/files/content/n55_australian_dietary_guidelines.pdf. 19. Reicks M, Kocher M, Reeder J. Impact of Cooking and Home Food Preparation Interventions Among Adults: A Systematic Review (2011-2016). J Nutr Educ Behav. 2018;50(2):148-72.

20. McGowan L, Pot GK, Stephen AM, Lavelle F, Spence M, Raats M, et al. The influence of socio-demographic, psychological and knowledge-related variables alongside perceived cooking and food skills abilities in the prediction of diet quality in adults: a nationally representative crosssectional study. Int J Behav Nutr Phys Act. 2016;13(1):111.

21. Reicks M, Trofholz AC, Stang JS, Laska MN. Impact of cooking and home food preparation interventions among adults: outcomes and implications for future programs. J Nutr Educ Behav. 2014;46(4):259-76.

22. Arabshahi S, Lahmann PH, Williams GM, Marks GC, van der Pols JC. Longitudinal change in diet quality in Australian adults varies by demographic, socio-economic, and lifestyle characteristics. J Nutr. 2011;141(10):1871-9.

23. Williams RL, Rollo ME, Schumacher T, Collins CE. Diet Quality Scores of Australian Adults Who Have Completed the Healthy Eating Quiz. Nutrients. 2017;9(8). 

cooking skills at different ages: a cross-sectional study. Int J Behav Nutr Phys Act. 2016;13(1):119. 25. Von Elm E, Altman DG, Egger M, Pocock SJ, Gøtzsche PC, Vandenbroucke JP. The Strengthening the Reporting of Observational Studies in Epidemiology (STROBE) statement: guidelines for reporting observational studies. Ann Int Med. 2007;147(8):573-7. 26. Australian Bureau of Statistics (ABS). Socio-Economic Indexes for Areas (SEIFA)2011 Available from: https://www.abs.gov.au/websitedbs/censushome.nsf/home/seifa.

27. Lavelle F, McGowan L, Hollywood L, Surgenor D, McCloat A, Mooney E, et al. The development and validation of measures to assess cooking skills and food skills. Int J Behav Nutr Phys Act. 2017;14(1):118.

28. Motteli S, Barbey J, Keller C, Bucher T, Siegrist M. Measuring practical knowledge about balanced meals: development and validation of the brief PKB-7 scale. Eur J Clin Nutr. 2016;70(4):505-10.

29. Roininen K, Tuorila H, Zandstra EH, de Graaf C, Vehkalahti K, Stubenitsky K, et al. Differences in health and taste attitudes and reported behaviour among Finnish, Dutch and British consumers: a cross-national validation of the Health and Taste Attitude Scales (HTAS). Appetite. 2001;37(1):33-45.

30. Collins CE, Burrows TL, Rollo ME, Boggess MM, Watson JF, Guest M, et al. The comparative validity and reproducibility of a diet quality index for adults: the Australian Recommended Food Score. Nutrients. 2015;7(2):785-98.

31. Scheffe H. The Analysis of Variance. New York, United States John Wiley \& Sons Inc 1959. 32. Dean M, Raats MM, Grunert KG, Lumbers M. Factors influencing eating a varied diet in old age. Public Health Nutr. 2009;12(12):2421-7. PubMed PMID: 19344544.

33. Horng JS, Hu ML. The Mystery in the Kitchen: Culinary Creativity AU - Horng, Jeou-Shyan. Creat Res J. 2008;20(2):221-30.

34. Stierand M, Lynch P. The Art of Creating Culinary Innovations. Tour Hosp Res. 2008;8(4):337-50.

35. Ottenbacher M, Harrington RJ. The innovation development process of Michelin-starred chefs. Int J Contemp Hospit Manag. 2007;19(6):444-60.

36. Ang L, Welling R. Self-branding, 'micro-celebrity' and the rise of Social Media Influencers AU - Khamis, Susie. Celebrity Studies. 2017;8(2):191-208.

37. Jones MT. A celebrity chef goes global: the business of eating. J Bus Strategy. 2009;30(5):1423.

38. de Solier I. TV Dinners: Culinary Television, Education and Distinction AU - de Solier, Isabelle. Continuum. 2005;19(4):465-81.

39. Caraher M, Lange T, Dixon P. The Influence of TV and Celebrity Chefs on Public Attitudes and Behavior Among the English Public AU - Caraher, Martin. Journal for the Study of Food and Society. 2000;4(1):27-46.

40. Larson NI, Perry CL, Story M, Neumark-Sztainer D. Food preparation by young adults is associated with better diet quality. J Am Diet Assoc. 2006;106(12):2001-7.

41. Winkler E, Turrell G. Confidence to cook vegetables and the buying habits of Australian households. J Am Diet Assoc. 2009;109(10):1759-68. 